\title{
Assessment of Factors Affecting Implementation of Nursing Process Among Nurses in Selected Governmental Hospitals, Addis Ababa, Ethiopia; Cross Sectional Study
}

\author{
Mulugeta Aseratie ${ }^{1}$, Rajalakshmi Murugan ${ }^{2}$ and Mulugeta Molla ${ }^{* 3}$ \\ ${ }^{1}$ Department of Nursing, College of Health Science, Addis Ababa Science and Technology University, Addis Ababa Ethiopia \\ ${ }^{2}$ School of Nursing, College of Health Science, Addis Ababa University, Addis Ababa, Ethiopia \\ ${ }^{3}$ Department of Nursing, College of Health Science, Mekelle University, Mekelle, Ethiopia \\ ${ }^{*}$ Corresponding author: Mulugeta Molla, Department of Nursing, College of Health Sciences, Mekelle University, Tigray, Ethiopia, P.O. Box 187, Tel: \\ +251-910-883-864; E-mail: muler.warso@gmail.com
}

Received date: March 10, 2014, Accepted date: May 30, 2014, Published date: June 3, 2014

Copyright: @ 2014 Aseratie M, et al. This is an open-access article distributed under the terms of the Creative Commons Attribution License, which permits unrestricted use, distribution, and reproduction in any medium, provided the original author and source are credited.

\begin{abstract}
Background: Nursing Process is a systematic problem-solving approach used to identify, prevent and treat actual or potential health problems and promote wellness. It has five steps- assessment, diagnosis, planning, implementation, and evaluation.
\end{abstract}

Objective: To assess factors affecting implementation of nursing process among nurses in selected governmental hospitals from February-April, 2011 at Addis Ababa, Ethiopia.

Method: A cross-sectional quantitative study was conducted on selected governmental hospitals in Addis Ababa. Purposive sampling was used for selection of hospitals. Black Lion, St. Paul, Ras Desta Damitew Memorial, and Yekatit 12 hospitals were convenient for the study. The sample size was 202. Data was analyzed using SPSS 16th version.

Result: Nurses working in a stressful working environment were 2.8 (adjusted OR: 0.357, 95\%Cl: $(0.157-0.814)$ ) times less likely to implement nursing process than disorganized working environment adjusting for facility accessibility, knowledge, and sex. Forty eight (25\%) of respondents were anxious from high patient flow. Among those $15(31.3 \%), 22(45.8 \%)$, and $11(22.9 \%)$ have committed knowledge, executive, and slip/slap error respectively. Highly knowledgeable respondents were 38.913 (Adjusted OR: 38.913, 95\% Cl: (10.3-147.006) times more likely to implement nursing process than low knowledge group nurses adjusted for working environment, facility, and sex.

Conclusion: The study has identified organizational factors, patient related factors, and level of knowledge and skill were among those factors highly influenced nursing process implementation. This factors cause poor quality of nursing care, disorganized caring system, conflicting role, medication error and readmission with similar problem, dissatisfaction with the care patients have received, and increased mortality.

Keywords: Nursing process; Factors; Ethiopia and hospitals

\section{Introduction}

Based on a nursing theory developed by Ida Jean Orlando in the late 1950 's as she observed nurses in action, the Nursing Process is an essential part of the nursing care plan [1].

The Nursing Process is a systematic problem-solving approach used to identify, prevent and treat actual or potential health problems and promote wellness. It has five steps; Assessment, Diagnosis, planning, implementation and evaluation [2].

Despite their knowledge of the nursing process, certain factors limited the ability of nurses to implement it in their daily practice, including lack of time, high patient volume, and high patient turnover. Despite these hurdles, the daily application of the nursing process is characterized by the scientific background of the professionals involved since it requires knowledge and provides individualized human assistance [3].

However, the existence of failures was shown among the nursing diagnoses in the patients' history, as well as the implementation of nursing prescriptions without recording the evaluation of the expected results [4].

Similar results were also shown in a study published in 2006 during the implementation of the nursing diagnosis, in which the research subjects indicated difficulties in developing the nursing process at all stages, and the need for changes to speed up the work process and optimize the quality of actions in care and education [5]. This research was done in University hospital where students are doing clinical practice. Students who attached in those hospitals learn from patient records but if there is no full implementation of nursing process, they cannot obtain what they should get from patient record. Furthermore, the patient care outcome might be poor which results into poor quality of life. Poor quality of life of an individual is one determinant factor 
for family disturbance. Family health will be impaired and societal problem become complicated.

It is reasonable to conclude that the nursing process is important for the practice of nursing; however, its use is not an easy task. Therefore, a continuous evaluation of how the nursing process is executed within the health services is required [6].

Nurses comprise the key connective tissue for Ethiopia's health care. They are also the largest cadre of health-care providers in Ethiopia and function in many different roles, from traditional bedside nursing to primary health care in regional health centers. It is common to see nurses working as laboratory personnel, dentists, councilors, and social workers to accommodate the shortages [7].

Nursing process is a multipurpose approach that enables nurses to perform their activities with logical justification. It safeguards the right of both the patient and the nurse. Recently in Ethiopia clients accuse nurses due to their haphazard practice. Clinton foundation is now giving in service training for nurses working in hospitals. Following this, training nurses are trying to practice nursing process and it becomes the focus of Ministry of Health throughout the country.

Nursing process implementation could be highly influenced by different factors that can lead to Poor quality of nursing care, disorganization of the service, conflicting roles, medication error, poor diseases prognosis, readmission, dissatisfaction with the care provided, and increased mortality. These problems are manageable if a nurse can properly implement nursing process. Therefore, the main aim of this study was to assess factors affecting implementation of nursing process among nurse in selected governmental hospitals of Addis Ababa. The finding will provide pragmatic evidence for educators, clinicians, program planner, decision makers to design a new and/or strengthen the existing nursing process and it will also serve as a baseline for future researchers.

\section{Materials and Methods}

\section{Study area}

The study was conducted in Addis Ababa, the capital city of Ethiopia and seat of African Union \& United Nations World Economic Commission for Africa. Addis Ababa has a population size of over 3 million. Its average elevation is $2,500 \mathrm{~m}$ above sea level, and hence has a fairly favorable climate and moderate weather conditions. There were 12 governmental hospitals, among these Black Lion, St. Paul, Ras Desta Damitew Memorial, and Yekatit provides multidimensional aspects of care to clients. The data was collected in those areas only because the rest were giving a specialized care for homogeneous groups and it would be difficult to analyze with the findings of those 4 hospitals.

\section{Study design}

Institution based quantitative cross sectional study was conducted in four selected governmental hospitals in Addis Ababa.

\section{Study period}

The study was conducted from February-April, 2011.

\section{Sample size determination}

The overall minimum sample size was determined using single population proportion formula by considering; $\mathrm{Z}=$ standard normal distribution $(Z=1.96)$ with confidence interval of $95 \%$ and $=0.05$, $\mathrm{p}=0.5, \mathrm{~d}=0.05$. And By assuming this the final sample size was calculated as:

$$
\mathrm{n} i=\frac{z_{\alpha / 2}^{2}(p(1-p))}{d^{2}}
$$

Where $\mathrm{n}=$ minimum sample size required for the study

$\mathrm{P}=$ prevalence/ population proportion $(\mathrm{p}=0.5)$; since we didn't get other $\mathrm{p}$-value we took $\mathrm{p} \_0.5$.

$\mathrm{d}=\mathrm{is}$ a tolerable margin of error $(\mathrm{d}=0.05)$

$$
=1.96(1.96)(0.5(1-0.5)) / 0.05(0.05)=384.16=>\mathrm{n}^{i}=384
$$

Since the total population is less than 10,000 we used correction formula. The exact sample size therefore was calculated as follows.

$$
\begin{aligned}
& f \frac{n_{i x} N}{n_{i}+N} \text { Where } \mathrm{n} i=\text { calculated sample size } \mathrm{n} f=\text { exact sample size } \\
& \mathrm{N}=\text { sample population } \\
& =(384 \times 354) /(384+354)=135,936 / 738=184.19=184 \\
& =184+10 \% \text { none response rate }=184+18.4=202.4 \\
& =202
\end{aligned}
$$

\section{Sampling procedure and technique}

According to the data obtained from the selected hospitals there were 126, 100, 59, and $69 \mathrm{BScN}$ nurses in BLH (Black lion Hospital), SPH (St. Paul), RDDMH (Ras Deasta Damtew Memorial Hospital), and Yekatit 12 hospital respectively. There were a total of $354 \mathrm{BScN}$ nurses.

For the hospitals to proportionate the number of study subject using $\mathrm{nf} / \mathrm{N} \mathrm{x} \mathrm{n}$, is allocated a proportionate sample to their size.

$$
\begin{aligned}
& \mathrm{BLH}=(202 \times 126) / 354=71.89=72 \\
& \mathrm{SPH}=(202 \times 100) / 354=57.06=57 \\
& \mathrm{RDDMH}=(202 \times 59) / 354=33.66=34 \\
& \text { Yekatit } 12=(202 \times 69) / 354=39.3=39
\end{aligned}
$$

Among those participants, Simple random sampling method has been used to select the participants from each Hospital.

\section{Data collection and quality control}

For data collection structured questionnaire was used. Structured English version questionnaire was developed from different literatures. And it was collected by self-administered questionnaire. The data collection process was supervised by the principal investigator from February-April/2011. Before the actual data collection, data collectors have obtained half day training about the aim of the study and the content of the instrument. 
Citation: Aseratie M, Murugan R, Molla M (2014) Assessment of Factors Affecting Implementation of Nursing Process Among Nurses in Selected Governmental Hospitals, Addis Ababa, Ethiopia; Cross Sectional Study . J Nurs Care 3: 170. doi:10.4172/2167-1168.1000170

Page 3 of 8

\section{Study variables}

The outcome variable was the Implementation of nursing process and the independent variable includes: Year of experience, Knowledge of nurses, Nurse to patient ratio, Nurse demographics, Hospital organizational structure, Patient turn over and Skill.

\section{Eligibility criteria}

\section{Inclusion criteria:}

- All BSc nurses with more than 6 months of working experience.

- Nurses who were willing to participate in the study.

\section{Exclusion criteria:}

- Diploma clinical nurse

- Nurses who are giving free service, absent during data collection time

\section{Statistical analysis}

Data first was cleared, coded and entered into computer using Epiinfo and exported into SPSS16 $6^{\text {th }}$ version for analysis. The Uni-variate analysis such as percentage and frequency distribution of different characteristics of the questionnaire were analyzed. Bivariate analysis was used to see the association of independent with the dependent variable. Logistic regression model was employed to control confounding variables, variables included in the model were restricted to those significantly related to implementation of nursing process at the bivariate level and some of the statistical test like, odds' ratio (crude \& adjusted) was used to measure their association and some of the results were compared with results of other studies available.

\section{Ethical considerations}

Ethical clearance was obtained from institutional review board of Addis Ababa University and selected hospital officials was communicated using support letter from school of nursing. No personal identification was registered and confidentiality was also maintained. No raw data was given to other parties

\section{Result}

In this study the response rate was 95\%. Among the total respondents $102(53.1 \%)$ were females and 90(46.9\%) were males. Ninety two $(47.9 \%)$ of the respondents were in the age range of below 24 years, $81(42.2 \%)$ were in $25-44$ years. one hundred fifty seven $(81.8 \%)$ of the respondents were worked overtime. Only $9(5.7 \%)$ of the respondents were satisfied with the overtime payment whereas 148 (94.3\%) were not satisfied with the payment (Table 1).

\begin{tabular}{|l|l|l|l|}
\hline \multicolumn{2}{|l|}{ Characteristics } & Frequency & Percentage \\
\hline sex & Female & 102 & 53.1 \\
\hline
\end{tabular}

\begin{tabular}{|c|c|c|c|}
\hline & Male & 90 & 46.9 \\
\hline \multirow[t]{4}{*}{ age } & below24 & 92 & 47.9 \\
\hline & $25-44$ & 81 & 42.2 \\
\hline & $45-54$ & 17 & 8.9 \\
\hline & $55-64$ & 2 & 1 \\
\hline \multirow[t]{4}{*}{ marital status } & Single & 135 & 70.3 \\
\hline & Married & 52 & 27.1 \\
\hline & Widowed & 3 & 1.6 \\
\hline & Divorced & 2 & 1 \\
\hline \multirow[t]{4}{*}{ year of graduation } & $<2 \mathrm{yrs}$ & 130 & 67.7 \\
\hline & $2-5 y r s$ & 57 & 29.7 \\
\hline & $5-10 y r s$ & 3 & 1.6 \\
\hline & $>10 \mathrm{yrs}$ & 2 & 1 \\
\hline \multirow[t]{6}{*}{ work experience } & $<5$ years & 144 & 75 \\
\hline & 5 -10years & 23 & 12 \\
\hline & $10-15$ years & 7 & 3.65 \\
\hline & $15-20$ years & 9 & 4.69 \\
\hline & $20-25$ years & 5 & 2.6 \\
\hline & $>25$ years & 4 & 2.1 \\
\hline
\end{tabular}

Table 1: Socio-demographic characteristics of nurses in governmental hospitals of Addis Ababa, Ethiopia, 2011.

Vis-à-vis on method of making work of nurses visible one hundred sixteen (60.4\%), 100(52.1\%), 33(17.2\%), and 68(35.4\%) of the respondents have used recording, nursing process, reporting to higher officials, and only working on the patient's problem to make their work visible respectively. Nine $(4.7 \%)$ of the respondents have used nothing to make their work visible. From the total respondents $116(60.4 \%)$ of them were always record their activities while $4(2.1 \%)$ never recorded their activities.

In this study forty eight (25\%) of respondents were anxious from high patient flow. Among those 15(31.3\%), 22(45.8\%), and 11(22.9\%) have committed knowledge, executive, and slip/slap error respectively.

From the total respondents 104(54.2\%) of them said the dissatisfying aspect of their job was caring for so many patients followed by rules being made up without staff or residents in mind 79(41.1\%); useless paper work $40(20.8 \%)$ and new reporting system $31(16.1 \%)$. From those dissatisfied with any reason stated above 95(49.5\%) of the total respondents were dissatisfied due to their profession (Table 2).

\begin{tabular}{|l|l|l|l|l|}
\hline Character & \multicolumn{1}{l|}{ Frequency } & Percentage \\
\hline \multirow{2}{*}{ Working hours/day } & $<8 \mathrm{hrs}$ & 11 & 5.7 \\
\cline { 2 - 5 } & $8 \mathrm{hrs}$ & 148 & 77.1 & \\
\hline
\end{tabular}


Citation: Aseratie M, Murugan R, Molla M (2014) Assessment of Factors Affecting Implementation of Nursing Process Among Nurses in Selected Governmental Hospitals, Addis Ababa, Ethiopia; Cross Sectional Study . J Nurs Care 3: 170. doi:10.4172/2167-1168.1000170

Page 4 of 8

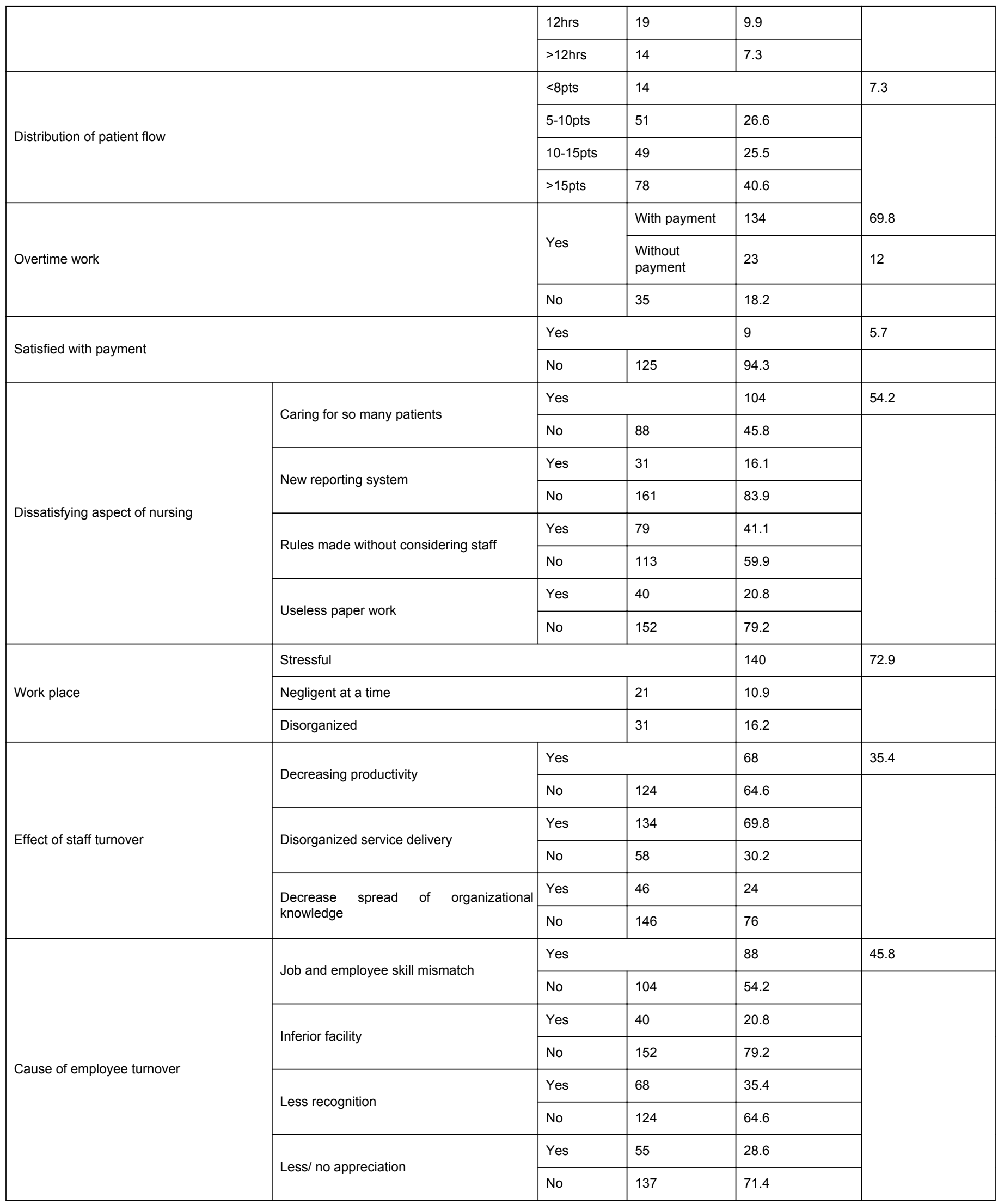


Citation: Aseratie M, Murugan R, Molla M (2014) Assessment of Factors Affecting Implementation of Nursing Process Among Nurses in Selected Governmental Hospitals, Addis Ababa, Ethiopia; Cross Sectional Study . J Nurs Care 3: 170. doi:10.4172/2167-1168.1000170

Page 5 of 8

\begin{tabular}{|l|l|l|l|l|l|}
\hline \multirow{4}{*}{} & \multirow{2}{*}{ Less growth opportunity } & Yes & 68 & 35.4 \\
\cline { 3 - 5 } & \multirow{3}{*}{ Poor training } & No & 124 & 64.6 \\
\cline { 3 - 5 } & \multirow{2}{*}{ Poor supervision } & Yes & 41 & 21.4 \\
\cline { 3 - 5 } & No & 151 & 78.6 \\
\hline
\end{tabular}

Table 2: Organizational factors affecting implementation of nursing process among Nurses in governmental hospitals of Addis Ababa, Ethiopia, 2011

Regarding working hour distribution (Table 2) seventy eight $(40.6 \%)$ of nurses have cared for more than 15 patients per day and $49(22.5 \%)$ were cared for 10-15 patients per day while 51(26.6\%) have cared for 5-10 patients per day and only 11(5.7\%) were cared for less than 8 patients per day. 148(77.1\%) of respondents have worked eight hours per day whereas $14(7.3 \%)$ have worked more than 12 hours per day.

Seventy eight $(40.6 \%)$ of respondents were challenged to provide their nursing care due to early discharge of patients before completing the planned intervention. Seventy five (39.1\%) of respondents believed that patients discharged before completing their treatment and came back to their institution with a complicated problem which was difficult to manage.

Regarding the knowledge assessment of nurses (Table 3) majority of respondents $175(91.1 \%)$ have answered the correct answer, which is evidence based practice is not among the five components of nursing process while the remaining $16(8.9 \%)$ have chosen the incorrect answer one among the components of nursing process.

\begin{tabular}{|l|l|l|l|}
\hline Characteristics & $\begin{array}{l}\text { Correct Answer No } \\
(\%)\end{array}$ & $\begin{array}{l}\text { Incorrect Answer No } \\
(\%)\end{array}$ & $\begin{array}{l}\text { Total } \\
\text { No (\%) }\end{array}$ \\
\hline One is not among the component of nursing process & $175(91.1 \%)$ & $17(8.9 \%)$ & $192(100 \%)$ \\
\hline A nurse should do one at the first step of nursing process & $156(81.2 \%)$ & $36(19.8 \%)$ & $192(100 \%)$ \\
\hline The Gordon approach is directly targeted at---- & $102(53.1 \%)$ & $90(46.9 \%)$ & $192(100 \%)$ \\
\hline $\begin{array}{l}\text { Which nursing diagnosis is better to solve a patient's problem with diabetes mellitus chronic } \\
\text { complication in the future? }\end{array}$ & $136(70.8 \%)$ & $56(29.2 \%)$ & $192(100 \%)$ \\
\hline What makes nursing process different from medical approach? & $137(71.4 \%)$ & $55(28.6 \%)$ & $192(100 \%)$ \\
\hline $\begin{array}{l}\text { Among the individuals in a hospital one is not mandatory for the better accomplishment of } \\
\text { nursing process. }\end{array}$ & $101(52.6 \%)$ & $91(47.4 \%)$ & $192(100 \%)$ \\
\hline $\begin{array}{l}\text { One is not included under the activities to be performed in the planning phase of nursing } \\
\text { process. }\end{array}$ & $64(33.3 \%)$ & $128(66.7 \%)$ & $192(100 \%)$ \\
\hline In implementation step of nursing process a nurse is expected to perform----- & $108(56.2 \%)$ & $84(43.8 \%)$ & $192(100 \%)$ \\
\hline One could not be a guide for evaluation of nurses performance in nursing process & $112(58.3 \%)$ & $80(41.7 \%)$ & $192(100 \%)$ \\
\hline $\begin{array}{l}\text { Disturbed sleeping pattern related to unresolved fears and anxieties as evidenced by } \\
\text { difficulty in falling /remain asleep. Identify the problem, etiology and sign/symptom of the } \\
\text { above nursing diagnosis }\end{array}$ & $92(47.9 \%)$ & $100(52.1 \%)$ & $192(100 \%)$ \\
\hline Write one full actual nursing diagnosis & & $15(20.3 \%)$ & $192(100 \%)$ \\
\hline
\end{tabular}

Table 3: Nurses' knowledge about nursing process among nurses in selected governmental hospitals of Addis Ababa, Ethiopia, 2011.

Regarding factors affecting of implementation of nursing process (Table 4) sixty one (32.8\%) of female and $39(20.3 \%)$ of male respondents were implemented nursing process. Out of one hundred respondents who were implemented nursing process $80(41.6 \%)$ were working in a stressful working environment, 10(5.2\%) were worked in a neglecting environment, and $10(5.2 \%)$ were worked in a disorganized environment. Seventy three (38\%) were implemented nursing process without facility shortage while $27(14 \%)$ were implemented with an inferior facility. Among those implemented nursing process only four nurses were highly knowledgeable and equal number of respondents 48(25\%) were moderately and poorly knowledgeable. 


\begin{tabular}{|c|c|c|c|c|c|c|}
\hline \multirow{2}{*}{\multicolumn{2}{|c|}{ Characteristics }} & \multicolumn{2}{|c|}{ Implementation of nursing process } & \multirow{4}{*}{\begin{tabular}{l|l|}
$\begin{array}{l}\text { Crude } \\
\text { value }\end{array}$ & $P-$ \\
$(95 \% \mathrm{Cl})$ & \\
0.023
\end{tabular}} & \multirow{4}{*}{\begin{tabular}{|l|} 
COR \\
\\
$0.514(0.289-0.913)$ \\
\end{tabular}} & \multirow{4}{*}{$\begin{array}{l}\text { AOR(95\%Cl) } \\
\\
0.712(0.361-1.407)^{*}\end{array}$} \\
\hline & & \multirow{3}{*}{$\begin{array}{l}\text { Yes } \\
\text { No }(\%) \\
61(32.8 \%)\end{array}$} & \multirow{3}{*}{$\begin{array}{l}\text { No } \\
\text { No }(\%) \\
41(21.4 \%)\end{array}$} & & & \\
\hline & & & & & & \\
\hline \multirow{2}{*}{ Sex } & Female & & & & & \\
\hline & Male & $39(20.3 \%)$ & $51(26.6 \%)$ & & & \\
\hline & Stress full & $80(41.6 \%)$ & $60(31.3 \%)$ & 0.014 & $0.357(0.157-0.814)$ & $0.180(0.065-0.501)$ \\
\hline \multirow[t]{2}{*}{ Work place } & Negligent & $10(5.2 \%)$ & $11(5.7 \%)$ & 0.266 & & \\
\hline & Disorganized & $10(5.2 \%)$ & $21(10.9 \%)$ & & & \\
\hline \multirow{2}{*}{ Facility } & Accessible & $73(38 \%)$ & $79(41.1 \%)$ & 0.031 & $2.248(1.079-4.684)$ & $3.109(1.277-7.570)$ \\
\hline & Inferior & $27(14 \%)$ & $13(6.8 \%)$ & & & \\
\hline \multirow{3}{*}{ Knowledge } & Highly knowledgeable & $4(2.1 \%)$ & $27(6.8 \%)$ & 0 & 27(7.924-91.994) & $38.913(10.3-147.006)$ \\
\hline & Moderately knowledgeable & $48(25 \%)$ & $53(27.6 \%)$ & 0 & $4.417(2.1-9.289)$ & $4.913(2.178-11.084)$ \\
\hline & Low knowledgeable & $48(25 \%)$ & $12(41.1 \%)$ & & & \\
\hline
\end{tabular}

Table 4: Factors Affecting implementation of nursing process among nurses in selected governmental hospitals of Addis Ababa, Ethiopia, 2011.

From binary logistic regression analysis (Table 4) being a female were significantly associated with implementation of nursing process than male (COR: $0.514,95 \% \mathrm{CI}:(0.284-0.913)$, p: 0.023).

Working in a hospital with high facility were 2.248 times significantly and more likely to implement nursing process than those working in an inferior facility (COR: $2.248,95 \% \mathrm{CI}$ : (1.079-4.684), P: $0.030)$

Highly knowledgeable nurses were 27 times more likely and significantly associated with implementation of nursing process than low knowledge group nurses (COR: 27, 95\%CI: (7.924-91.994), P: $<0.001)$. Moderately knowledgeable nurses were positively and significantly associated with implementation of nursing process (COR: 4.417, 95\%CI: (2.1-9.289), P: <0.001).

In a multivariate analysis (multivariate logistic regression) (Table 4) nurses working in a stressful working environment were 0.357 (AOR: 0.357, (0.157-0.814)) times less likely to implement nursing process than disorganized working environment adjusting for facility accessibility, knowledge, and sex. Accessibility of facilities needed for nursing care were 2.248(AOR: 2.248, (1.079-4.684) times more likely to implement nursing process than nurses working in an inferior facility controlling for working environment, knowledge, and sex. Highly knowledgeable and highly skillful, moderately skillful, and poorly skillful accounting 19,11, and 1 respectively were 38.913(AOR: 38.913, (10.3-147.006) times more likely to implement nursing process than low knowledge group nurses adjusted for working environment, facility, and sex. Moderately knowledgeable were 4.913 (AOR: 4.913, (2.178-11.407)) times more likely to implement nursing process than low knowledge group nurses adjusted for work place, facility, and sex.

\section{Discussion}

The study tried to assess factors affecting implementation of nursing process among nurses working in selected government hospitals of Addis Ababa. One hundred (52.1\%) nurses were implemented nursing process while $92(47.9 \%)$ of them were not implemented nursing process. From those implemented nursing process $61(61 \%)$ were female and 39(39\%) were male.

From the total respondents 104 (54.2\%) of them said the dissatisfying aspect of their job was caring for so many patients. In a research conducted about nurse to physician communication, nursing workload definitely affects the time that a nurse can allot to various tasks. Under a heavy workload, nurses may not have sufficient time to perform tasks that can have a direct effect on patient safety. A heavy nursing workload can influence the care provider's decision to perform various procedures [8]. This similarity might be due to the nature of the profession and when nurses become dissatisfied about their job the nursing care to be provided will not have systematic approach or nursing process may not be implemented in a hospital with high patient flow beyond the capacity of nurses.

The average nurse-to-population ratio in high-income countries is almost eight times greater than in low-income countries. Factors contributing to the nursing shortage vary in different parts of the world [9]. As registered nurse-to-patient ratios decrease from 1:4 to $1: 10$, the number of post-op surgical patient deaths climbs dramatically [10]. In this study seventy eight (40.6\%) of nurses have cared for more than 15 patients per day and 49(22.5\%). This significant difference might be due to a difference in socio-economic status of those countries.

One hundred thirty four (69.8\%) of respondents in this study had believe that staff turn over from a specific public health institution obligates the organization to provide a disorganized service. Sixty eight $(35.4 \%)$ of respondents had believe that staff turnover can cause decrease in productivity whereas $46(24 \%)$ had believed that staff turnover can cause decreased spread of organizational knowledge. In line with this research, several studies have shown the relationship between nurses' working conditions, such as high workload, and job dissatisfaction [11]. Job dissatisfaction of nurses can lead to low morale, absenteeism, turnover, and poor job performance, and 
potentially threaten patient care quality and organizational effectiveness [12]. Thus, workload leads to staff turnover that could be a burdensome for implementation of nursing process.

According to the report released from Cambridge UK workload can be a factor contributing to errors [13]. In this study forty eight (25\%) of respondents were anxious from high patient flow. Among those 15(31.3\%), 22(45.8\%), and 11(22.9\%) have committed knowledge, executive, and slip/slap error respectively.

There was a study conducted in the United Kingdom to assess whether data obtained from nursing records could be reliably used to identify interventions for patients who had suffered acute myocardial infarction or a fracture of the head of the femur, showed that the analyzed nursing records did not provide an adequate picture of patients' needs for nursing interventions [14]. Similarly in this study ninety two $(47.9 \%)$ of respondents were able to identify the problem, etiology and sign and symptoms of a given actual nursing diagnosis. Only 39(20.3\%) of respondents were able to write a full actual nursing diagnosis that have consisted of problem, etiology, and manifestations of the problem. This tells us the inability of nurses to identify the components of nursing diagnoses and recording it in a well-organized manner that could be understandable by other staff members. This may be due to the difficulty of nurses to write nursing diagnosis than other nursing process components.

An investigation conducted in Brazil on the steps of nursing process actually implemented in the routine of a university hospital showed that all phases were performed. However, problems were identified in the nursing diagnosis process, involving recording the history and implementing nursing prescriptions. The evolution of expected results, in particular, was not adequately recorded [15]. From 100(52.1\%) respondents who have implemented nursing process $61,22,8,7$, and 2 were recorded their activities always, sometimes, every once in a while, rarely and never respectively. The part of nursing process which was not written is not separately identified in this study. But we can conclude that nurses could not fully document what they have performed cognizant of the fact that they have implemented nursing process.

High workload is a key job stressor of nurses in a variety of care settings, such as ICUs. A heavy nursing workload can lead to distress (e.g., cynicism, anger, and emotional exhaustion) and burnout. Nurses experiencing stress and burnout may not be able to perform efficiently and effectively because their physical and cognitive resources may be reduced; this suboptimal performance may affect patient care and its safety. In this study from the characteristics work place, nurses who were working in a stressful environment were 0.357 times significantly and less likely to implement nursing process than those worked in a disorganized environment (COR: 0357, 95\%CI (0.157-0.814), P: $0.014)$. Neglecting working environment had no significant association with implementation of nursing process. Hence nursing process implementation needs a safe and encouraging working environment.

\section{Conclusion}

From this study 100(52.1\%) of the respondents were implementing nursing process. Among the factors which affect the nursing process were high patient flow $48(25 \%)$, patient load $78(40.6 \%)$ of nurses cared for more than 15 patients per day, early discharge 78(40.6\%). Nurses who were working in a stressful environment were 0.357 times less likely to implement nursing process than those worked in a disorganized environment.
Highly knowledgeable nurses were $27 \%$ times more likely to implement nursing process than low knowledge group nurses.

\section{Strength and Limitation of the Study:}

\section{Strength of the study}

This study was probably the first/ among the pioneers research related to nursing process in Ethiopia. It will be helpful as baseline information for other researchers.

\section{Limitations of the study}

Since this was quantitative study it may not explore all the associated factors and it is advisable to use both quantitative and qualitative methods as well.

Since the study subjects were recruited from selected governmental hospitals of Addis Ababa. The study didn't included nurses working in other hospitals. Thus the study may not be generalized to all nurses in Addis Ababa because nurses out of selected hospitals may have different experience and opinion.

\section{Acronyms and Abbreviations}

\section{AAU: Addis Ababa University}

BLH: Black Lion Hospital

Dx:Diagnosis

ICU: Intensive Care Unit

NANDA: North American Nursing Diagnosis Association

NCP: Nursing Care Plan

NP: Nursing Process

RDDMH: Ras Desta Damitew Memorial Hospital

SPH: St. Paul Hospital

USA: United States of America

\section{Competing interest}

We don't have any competing interest.

\section{Acknowledgement}

Above all we would like to express our gratitude to my Lord- Jesus Christ and His mother the Virgin St. Marry who carries all my burdens and shepherded us healthy.

We are pleased to thank AtoFekadu Aga (MSN), AtoYosephTsgie (MSN), Addis Ababa University), AtoAbdurahman Mohamed(MPH), Dr.Mulusew A and his wife Etalemahu M. for their professional, moral and material support. Our gratitude also goes to our friends for their direct or indirect contribution to the development of this study.

The last but not the least we would like to extend our gratitude to data collectors, Addis Ababa University, staff of Black Lion, St. Paul, RasDestaDamitew, and Yekatit12 hospitals for their cooperation in the realization of the study. 
Citation: Aseratie M, Murugan R, Molla M (2014) Assessment of Factors Affecting Implementation of Nursing Process Among Nurses in Selected Governmental Hospitals, Addis Ababa, Ethiopia; Cross Sectional Study . J Nurs Care 3: 170. doi:10.4172/2167-1168.1000170

Page 8 of 8

\section{References}

1. CGS (2010) Nurse Practice Act

2. S Carlson (2010) Nursing Process

3. De Freitas MC, Queiroz TA, de Souza JA (2007) [The nursing process according to the view of nurses from a maternity]. Rev Bras Enferm 60 : 207-212.

4. Lima AF, Kurcgant P (2006) [The nursing diagnosis implementation process at the University Hospital of the University of São Paulo]. Rev Esc Enferm USP 40: 111-116.

5. Lima AF, Kurcgant P (2006) Meanings of the nursing diagnosis implementation process for nurses at a university hospital. Rev Lat Am Enfermagem 14: 666-673.

6. J Schaefer (2010) Nursing process and its determinant factors.

7. Global health council (2010) Building a Winning Nursing Work Force for HIV-Care in Ethiopia.

8. Griffith CH 3rd, Wilson JF, Desai NS, Rich EC (1999) Housestaff workload and procedure frequency in the neonatal intensive care unit. Crit Care Med 27: 815-820.
9. WHO (2006) The World Health Report 2006

10. Darvas JA, Hawkins LG (2002) What makes a good intensive care unit: a nursing perspective. Aust Crit Care 15: 77-82.

11. Cavanagh SJ (1992) Job satisfaction of nursing staff working in hospitals. J Adv Nurs 17: 704-711.

12. Reason J (1990) Human error. Cambridge, UK: Cambridge University Press.

13. Hale CA, Thomas LH, Bond S, Todd C (1997) The nursing record as a research tool to identify nursing interventions. J Clin Nurs 6: 207-214.

14. Reppetto MA, de Souza MF (2005) [Evaluation of nursing care systematization through the phases of nursing process performance and registration in a teaching hospital]. Rev Bras Enferm 58: 325-329.

15. Oates RK, Oates $P$ (1995) Stress and mental health in neonatal intensive care units. Arch Dis Child Fetal Neonatal Ed 72: F107-110. 